\title{
Effects of astaxanthin on antioxidant capacity of golden pompano (Trachinotus ovatus) in vivo and in vitro
}

\author{
Jia-jun Xie ${ }^{1,2+}, \mathrm{Xu}_{\text {Chen }}{ }^{1 \dagger}$, Jin Niu${ }^{3 *}$, Jun Wang ${ }^{1}$, Yun Wang ${ }^{1}$ and Qiang-qiang Liu ${ }^{1}$
}

\begin{abstract}
The objective of this research was to study the effect of astaxanthin (AST) on growth performance and antioxidant capacity in golden pompano (Trachinotus ovatus) both in vivo and in vitro. In the in vivo study, two diets were formulated with or without astaxanthin supplementation (D1 and D2; 0 and $200 \mathrm{mg} / \mathrm{kg}$ ) to feed fish for 6 weeks. In the in vitro study, cells from hepatopancreas of golden pompano were isolated and four treatments with or without astaxanthin and $\mathrm{H}_{2} \mathrm{O}_{2}$ supplementation were applied (control group: without both astaxanthin and $\mathrm{H}_{2} \mathrm{O}_{2}$ treated; $\mathrm{H}_{2} \mathrm{O}_{2}$ group: just with $\mathrm{H}_{2} \mathrm{O}_{2}$ treated; $\mathrm{H}_{2} \mathrm{O}_{2}+$ AST group: with both astaxanthin and $\mathrm{H}_{2} \mathrm{O}_{2}$ treated; AST group: just with AST treated). Results of the in vivo study showed that weight gain (WG) and special growth rate (SGR) significantly increased with astaxanthin supplemented $(P<0.05)$. Feed conversion ratio (FCR) of fish fed D2 diet was significantly lower than that of fish fed D1 diet $(P<0.05)$. Hepatic total antioxidant capacity (T-AOC) and the reduced glutathione (GSH) of golden pompano fed D2 diet were significant higher than those of fish fed D1 diet $(P<0.05)$. Superoxide dismutase (SOD) was significantly declined as astaxanthin was supplemented $(P<0.05)$. Results of the in vitro study showed that the cell viability of $\mathrm{H}_{2} \mathrm{O}_{2}$ group was $52.37 \%$ compared to the control group, and it was significantly elevated to $84.18 \%$ by astaxanthin supplementation $\left(\mathrm{H}_{2} \mathrm{O}_{2}+\right.$ AST group $)(P<0.05)$. The total antioxidant capacity (T-AOC) and the reduced glutathione (GSH) of cell were significant decreased by oxidative stress from $\mathrm{H}_{2} \mathrm{O}_{2}(P<0.05)$, but it could be raised by astaxanthin supplementation $\left(\mathrm{H}_{2} \mathrm{O}_{2} \mathrm{Vs}_{2} \mathrm{H}_{2}+\right.$ AST), and the malondialdehyde (MDA) was significant higher in $\mathrm{H}_{2} \mathrm{O}_{2}$ group $(P<0.05)$ and astaxanthin supplementation could alleviate the cells from lipid peroxidation injury. In conclusion, dietary astaxanthin supplementation can improve the growth performance of golden pompano. Moreover, astaxanthin can improve the golden pompano hepatic antioxidant capacity both in vivo and in vitro study by eliminating the reactive oxygen species.
\end{abstract}

Keywords: Golden pompano, Astaxanthin, Growth performance, Antioxidant capacity

\section{Background}

Reactive oxygen species (ROS) are oxidative products, produced continuously in the course of normal aerobic cellular metabolism and respiratory burst (Chew 1995), which participate in a variety of biological processes, including normal cell growth, induction and maintenance of the transformed state, programmed cell death, and cellular senescence (Finkel 2003). However, ROS can, in turn, damage healthy cells if they are not eliminated (Chew 1995). Under

\footnotetext{
*Correspondence: gzniujin2003@163.com; 1657864417@qq.com

${ }^{\dagger}$ Equal contributors

${ }^{3}$ Institute of Aquatic Economic Animals, School of Life Science, Sun Yat-sen University, NO.135 at Xingang Xi Road, Haizhu District, Guangzhou 510275, Guangdong Province, China

Full list of author information is available at the end of the article
}

normal physiological conditions, the excessive ROS can be removed by internal antioxidants and anti-oxidative systems (Chen et al. 2015), including counter balance such as enzymes (like superoxide dismutase, catalase, and glutathione peroxidase), functionalized large molecules (albumin, ferritin, and ceruloplasmin) and small molecules (ascorbic acid, $\alpha$-tocopherol, $\beta$-carotene, and uric acid) (Martinez-Alvarez et al. 2005). The dietary antioxidants most widely used include vitamin $\mathrm{E}$, vitamin $\mathrm{C}$, carotenoids, flavanoids, zinc, and selenium (Chew and Park 2004). Among those, carotenoids reach the highest plasma and tissue concentrations, despite their lower intake (Olmedilla et al. 2007).

Carotenoids, more than 600 known types, can be classified into two categories, xanthophyll and carotenes. 
Astaxanthin $\quad\left(3,3^{\prime}\right.$-dihydroxy- $\beta, \beta$-carotene- 4,4 ' dione, AST) is a xanthophyll carotenoid which is found in many microorganisms and marine animals, such as shrimp, crayfish, crustaceans, salmon, trout, krill, microalgae as well as yeast. Its molecule consists of 40 carbon atoms, divided into a central portion containing 22 carbon atoms linked with 13 conjugated double bonds and two terminal benzene rings containing hydroxyl and ketone groups, giving rise to the higher polar structure of AST compared with other carotenoids (Britton 1995).The antioxidant activity of astaxanthin was found to be approximately 10 times stronger than $\beta$-carotene (Shimidzu et al. 1996).

Except for its antioxidant capacity, AST is also recognized to have growth performance and survival rate promoting in Atlantic salmon (Salmo salar) (Christiansen and Torrissen 1996) and red porgy (Pagrus pagrus) (Kalinowski et al. 2011), skins coloration enhancing in large yellow croaker (Larimichthys croceus) (Yi et al. 2014) and Atlantic salmon(Baker et al. 2002), anti-lipid peroxidation (Leite et al. 2010), and immune response reinforcing in Astronotus ocellatus (Alishahi et al. 2015) properties.

Golden pompano (Trachinotus ovatus) belongs to family carangidae, genus Trachinotus. It is a warm-water species $\left(25-32{ }^{\circ} \mathrm{C}\right)$ and a carnivorous fish that preys mainly on zooplankton, small crustaceans, shellfish, and small fish (Liu and Chen 2009). T. ovatusis is widely distributed in China, Japan, Australia, and other countries (Huo-sheng 2006). Pompano is considered one of the most desirable food fishes, and it commands a significantly higher price than many other marine and freshwater species (Tutman et al. 2004). Recently, pompano is widely farmed owing to its high price in the market and resilience to salinity and temperature ranges (Tutman et al. 2004), and annual output was over 100,000 tons. The suitable dietary protein and lipid levels for golden pompano are 46.0 and 6.5\% (Wang et al. 2013). The optimum carbohydrate level for juvenile golden pompano could be $11.2-16.8 \%$ of the diet (Zhou et al. 2015). The optimal requirements of methionine (Niu et al. 2013), arginine (Lin et al. 2015), and n-6 long-chain polyunsaturated fatty acid arachidonic acid (ARA) (Qi et al. 2016) for golden pompano have been determined as well.

However, fewer studies were conducted to investigate the effects of antioxidants on golden pompano. To date, the effects of AST on various kinds of fishes are mainly reported in vivo and rarely found in vitro. We used in vivo and in vitro models to study and compare the effect of astaxanthin on antioxidant ability of golden pompano, respectively.

\section{Methods}

\section{Diet preparation and dietary treatments}

In this study, two isonitrogenous and isoenergetic semipurified diets were formulated supplementing with or without astaxanthin (D1: 0\%; D2: 0.2\%; CAROPHYLL
Pink, 10\% astaxanthin, DSM Nutritional Products France SAS) (Table 1). The method of diet preparation was the same as described by Niu et al. (2015). Briefly, all dry ingredients were finely ground, weighed, mixed manually for $5 \mathrm{~min}$, and then transferred to a Hobart mixer (A-200 T Mixer Bench Model unit; Resell Food Equipment Ltd., Ottawa, ON, Canada) for another 15 min mixing. During the mixing, $6 \mathrm{~N} \mathrm{NaOH}$ was added to establish a $\mathrm{pH}$ level of 7-7.5. The $\mathrm{pH}$ of the diet was obtained by homogenizing a 5 -g portion of the diet with $50 \mathrm{~mL}$ of distilled water with a glass-electrode $\mathrm{pH}$ meter on the supernatant (Robinson et al. 1981). Soya lecithin was added to pre-weighed fish oil and mixed until homogenous. The oil mix was then added to the Hobart mixer slowly while mixing was still continuing. All ingredients were mixed for another $10 \mathrm{~min}$. Then, distilled water (about 30-35\%,v/w) was added to the mixture to form dough. Dough of even consistency was passed through a pelletizer with a 2.5 -mm-diameter

Table 1 Ingredients and proximate composition of the two experimental diets (\%)

\begin{tabular}{|c|c|c|}
\hline Ingredients & Diet 1 & Diet 2 \\
\hline Fish meal & 32.00 & 32.00 \\
\hline Soybean meal & 30.00 & 30.00 \\
\hline Wheat flour & 20.00 & 19.80 \\
\hline Krill meal & 2.00 & 2.00 \\
\hline Fish oil & 8.00 & 8.00 \\
\hline Soya lecithin & 2.00 & 2.00 \\
\hline Monocalcium phosphate & 2.00 & 2.00 \\
\hline Pre-vitamin ${ }^{a}$ & 1.00 & 1.00 \\
\hline Pre-mineral $^{\mathrm{b}}$ & 1.00 & 1.00 \\
\hline Choline & 0.50 & 0.50 \\
\hline Vc & 0.50 & 0.50 \\
\hline DL-Met & 0.40 & 0.40 \\
\hline Lys-HCL (78\%) & 0.60 & 0.60 \\
\hline AST & 0 & 0.20 \\
\hline Sum & 100 & 100 \\
\hline \multicolumn{3}{|l|}{ Nutrient levels } \\
\hline Moisture & 9.00 & 7.54 \\
\hline Crude protein & 40.64 & 40.55 \\
\hline Crude fat & 10.71 & 10.90 \\
\hline Ash & 15.21 & 15.24 \\
\hline
\end{tabular}

aPre-vitamin (mg or $\mathrm{g} \mathrm{kg}^{-1}$ diet): thiamin, $25 \mathrm{mg}$; riboflavin, $45 \mathrm{mg}$; pyridoxine $\mathrm{HCl}, 20 \mathrm{mg}$; vitamin B12, $0.1 \mathrm{mg}$; vitamin K3,10 mg; inositol, $800 \mathrm{mg}$; pantothenic acid, $60 \mathrm{mg}$; niacin acid, $200 \mathrm{mg}$; folic acid, $20 \mathrm{mg}$; biotin, $1.20 \mathrm{mg}$; retinal acetate, $32 \mathrm{mg}$; cholecalciferol, $5 \mathrm{mg}$; a-tocopherol, $120 \mathrm{mg}$; ascorbic acid, $2000 \mathrm{mg}$; choline chloride, $2500 \mathrm{mg}$; ethoxyquin $150 \mathrm{mg}$; and wheat middling, $14.012 \mathrm{~g}$ (Niu et al. 2013)

${ }^{\mathrm{b}}$ Pre-mineral (mg or g kg ${ }^{-1}$ diet): $\mathrm{NaF}, 2 \mathrm{mg} ; \mathrm{Kl}, 0.8 \mathrm{mg} ; \mathrm{CoC}_{\mathrm{i}_{2}} 6 \mathrm{H}_{2} \mathrm{O}(1 \%)$, 50 mg; $\mathrm{CuSO}_{4} 5 \mathrm{H}_{2} \mathrm{O}, 10$ mg; $\mathrm{FeSO}_{4} \mathrm{H}_{2} \mathrm{O}, 80 \mathrm{mg} ; \mathrm{ZnSO}_{4} \mathrm{H}_{2} \mathrm{O}, 50 \mathrm{mg} ; \mathrm{MnSO}_{4} \mathrm{H}_{2} \mathrm{O}$, $60 \mathrm{mg} ; \mathrm{MgSO}_{4} 7 \mathrm{H}_{2} \mathrm{O}, 1200 \mathrm{mg} ; \mathrm{Ca}\left(\mathrm{H}_{2} \mathrm{PO}_{4}\right){ }_{2} \mathrm{H}_{2} \mathrm{O}, 3000 \mathrm{mg} ; \mathrm{NaCl}, 100 \mathrm{mg}$; and zoelite, $15.447 \mathrm{~g}$ (Niu et al. 2013) 
die (Institute of Chemical Engineering, South China University of Technology, Guangzhou, China). The diets were dried until the moisture was reduced to $<10 \%$. The dry pellets were placed in plastic bags and stored $20{ }^{\circ} \mathrm{C}$ until fed.

\section{Animal rearing and experimental procedures}

The feeding trial was conducted at an experimental station of South China Sea Fisheries Research Institute of Chinese Academy of Fishery Sciences (Sanya, Hainan). Prior to the start of the trial, juvenile T. ovatus were acclimated to a commercial diet for 2 weeks and were fed twice daily to apparent satiation. At the beginning of the feeding trial, the fish were starved for $24 \mathrm{~h}$, weighed, and then fish with similar size (initial body weight $23.65 \pm$ $0.10 \mathrm{~g})$ were randomly allotted to 8 sea cages $(1.0 \mathrm{~m} \times$ $1.0 \mathrm{~m} \times 1.5 \mathrm{~m}$; four cages per diet treatment); each cage was stocked with 30 fish. Each experimental diet was randomly assigned to four cages. The feeding frequency was once daily at 8:00 and lasted for 6 weeks. To prevent the waste of pellets, fish were slowly hand-fed to satiation based on visual observation of their feeding behavior. Feed consumption was recorded for each cage every day. Water quality parameters were monitored daily.

\section{Sample collection}

At the end of the feeding trial, fish were starved for $24 \mathrm{~h}$ and then weighed and counted the total number. Ten fish from each cage were randomly collected for sampling: four for analysis of whole-body composition and six were anesthetized to obtain weights of individual whole body, viscera, and liver. The livers were rapidly removed and frozen in the liquid nitrogen separately for analysis of lipid peroxidation and antioxidant status.

\section{Biochemical composition analysis}

Chemical composition of diets and fish were determined by standard methods (Latimer 2012). Moisture was determined by oven drying at $105{ }^{\circ} \mathrm{C}$ until a constant weight was obtained. Crude protein content $(N \times 6.25)$ was determined according to the Kjeldahl method after acid digestion using an Auto Kjeldahl System (1030Autoanalyzer; Tecator, Höganäs, Sweden). Crude lipid was determined by the ether extraction method using a Soxtec extraction System HT (Soxtec System HT6, Tecator). Ash content was determined after samples were placed in a muffle furnace at $550{ }^{\circ} \mathrm{C}$ for $4 \mathrm{~h}$.

\section{Isolation of liver cells}

Golden pompano was purchased from a market in Guangzhou, China. Hepatocytes were isolated according to the methods of Wan et al. (2004) with some modifications. In the procedure, a fish was kept in $0.01 \%$ potassium permanganate solution for half an hour, after that, its skin was sterilized by alcohol, and its abdomen was dissected with sterile instruments from the anus toward the head. Liver tissue was excised and rinsed three times with phosphate buffer solution. The liver tissue was then minced into pieces of $1 \mathrm{~mm}^{3}$ and transferred to a $15 \mathrm{~mL}$ tube to which a solution of $0.25 \%$ trypsin (1:20 w/v; Sigma) was added. The mixture was trypsinized on a thermostatic water bath to obtain the cell suspension, which was shaken every $5 \mathrm{~min}$. Then, the mixture was filtered through a 100-mesh sieve. The cell suspensions were pooled and centrifuged at $1000 \mathrm{rpm}$ for $10 \mathrm{~min}$, and the cell pellet was washed and resuspended in a culture medium. The cell number was counted using a haemocytometer, and cell viability was estimated immediately following isolation using the trypan blue exclusion assay.

\section{Cell culture and treatments}

A final cell density of hepatocytes was adjusted to $2 \times 10^{6}$ cells $\mathrm{mL}^{-1}$ in L-15 culture medium (Jinuo Co, Hangzhou, China) supplemented with $2 \mathrm{mM} \mathrm{L}$-glutamine (Sigma) and $10 \%$ foetal bovine serum (Gibco). Cells were seeded into 12-well culture plates with $500 \mu \mathrm{L}$ cell suspension per well. Cells were cultured in a humidified atmosphere at $28{ }^{\circ} \mathrm{C}$. Once seeded, cells were allowed to attach to culture plates for $24 \mathrm{~h}$. At $24 \mathrm{~h}, 50 \%$ of the culture medium $(250 \mu \mathrm{L})$ was removed and replaced with fresh medium. Then PBS, $100 \mathrm{mM} \mathrm{H}_{2} \mathrm{O}_{2}, 1000 \mathrm{ng} / \mathrm{mL}$ astaxanthin dissolved in dimethyl sulfoxide (DMSO) (final concentration $0.01 \%$ ), and $\mathrm{H}_{2} \mathrm{O}_{2}$ plus astaxanthin were added in the wells. Every treatment was replicated in three wells. Cell viability was evaluated by trypan blue exclusion test, and cells were harvested for antioxidant capacity analysis after the treatments. As an additional measure of cell viability, lactate dehydrogenase (LDH) activity in the extracellular medium (an indicator of membrane leakage (Misra and Niyogi 2009) was measured.

\section{Antioxidant capacity analysis}

Hepatic and cell samples were homogenized in ice-cold phosphate buffer (1:10 dilution) (phosphate buffer; $0.064 \mathrm{M}$, $\mathrm{pH}$ 6.4). The homogenate was then centrifuged for $20 \mathrm{~min}$ $\left(4{ }^{\circ} \mathrm{C}, 3000 \mathrm{~g}\right)$, and aliquots of the supernatant were used to quantify hepatic T-AOC, GSH, SOD, and MDA.

The levels of enzyme activity and lipid peroxidation were measured with commercial ELISA kits (Randox Laboratories Ltd.) in accordance with the instructions of the manufacturer. The assays are briefly described as follows: The T-AOC is the representative of enzyme and nonenzyme original antioxidant in the body; these antioxidants can reduce the ferric ion $\left(\mathrm{Fe}^{3+}\right)$ to ferrous ion $\left(\mathrm{Fe}^{2+}\right)$. The latter combines with phenanthroline and produces a stable chelate, which can be measured by spectrophotography at $520 \mathrm{~nm}$ (Xiao et al. 2004). The T-AOC was determined in units per milligram of tissue protein. 
Total superoxide dismutase (SOD) activity was measured by using a xanthine oxides (Marklund and Marklund 1974). The ratio of autooxidation rates of the samples with or without hepatic homogenate was determined at $550 \mathrm{~nm}$. One unit of SOD activity was calculated using the amount of superoxide dismutase required to inhibit the reduction of nitrobluete trazolium by $50 \%$.

The formation of 5-thio-2-nitrobenzoate (TNB) was followed spectrophotometrically at $412 \mathrm{~nm}$ (Vardi et al. 2008). The amount of GSH in the extract was determined as $\mu \mathrm{mol} / \mathrm{mg}$ protein utilizing a commercial GSH as the standard. The results are expressed as $\mu \mathrm{mol} / \mathrm{mg}$ protein.

Lipid-peroxidation levels were determined based on the malondialdehyde (MDA) level generated by oxidizing fatty acids. In the presence of thiobarbituric acid, malondialdehyde started producing colored thiobarbituricacid-reacting substances (TBARS) that were measured at $532 \mathrm{~nm}$ (Buege and Aust 1978).

Lactate dehydrogenase (LDH) can catalyze lactate into pyruvate, which react with 2,4-dinitrophenylhydrazine and produce a stable compound, which was measured by spectrophotography at $450 \mathrm{~nm}$.

\section{Calculations and statistical analysis}

The parameters were calculated as follows:

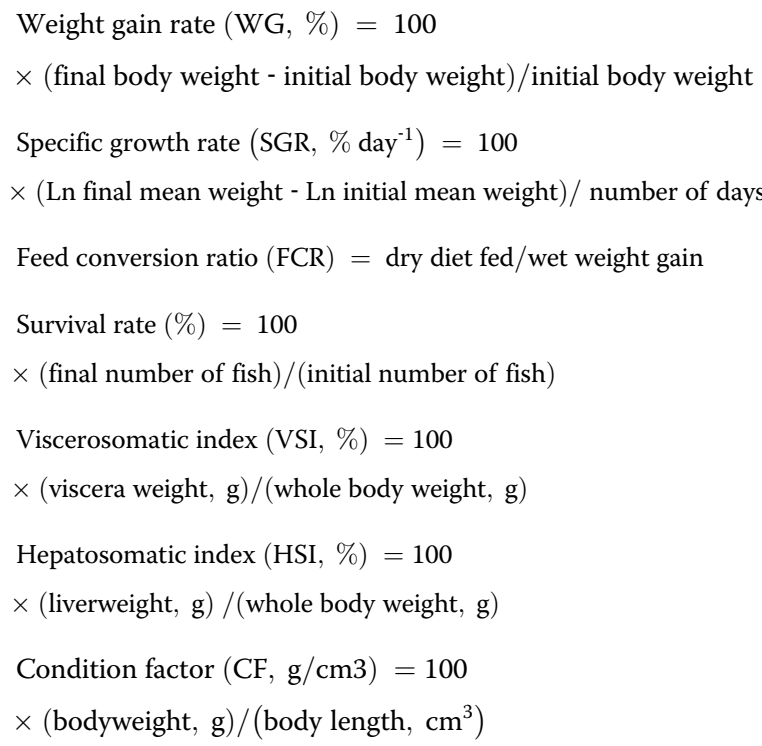

Data from each treatment were subjected to one-way analysis of variance (ANOVA). Homogeneity of variance was verified using Bartlett and Levene's test. When overall differences were significant, Tukey's multiple range tests was used to compare the mean values among individual treatments. The level of significant difference was set at $P<0.05$. Statistical analysis was performed using the SPSS19.0 (SPSS Inc., Michigan Avenue, Chicago, IL, USA) for Windows, and the results are presented as means \pm SEM (standard error of the mean).

\section{Results}

\section{Growth performance in vivo}

Growth, feed utilization, and biometric parameters of juvenile pompano fed different dietary astaxanthin levels are shown in Table 2. Results showed that final body wet weight (FBW), weight gain (WG), and special growth rate (SGR) significantly increased with astaxanthin supplemented $(P<0.05)$. Feed conversion ratio $(\mathrm{FCR})$ of golden pompano fed the diets supplemented with astaxanthin was significantly lower than that of fish fed the control diet $(P<0.05)$, while no significant differences were found in survival rate between the two diet treatments $(P>0.05)$. Hepatosomatic somatic indices (HSI), visceral somatic indices (VSI), and condition factor (CF) were significantly decreased in astaxanthin-supplemented diet treatment.

\section{Growth performance in vitro}

In the in vitro study, the cell viability of $\mathrm{H}_{2} \mathrm{O}_{2}$ group was $52.37 \%$ compared to the control group (PBS group), and it could be significantly elevated to $84.18 \%$ with astaxanthin supplementation $\left(\mathrm{H}_{2} \mathrm{O}_{2}+\right.$ AST group $)(P<0.05)$ (Fig. 1). The highest lactate dehydrogenase (LDH) activity was found in $\mathrm{H}_{2} \mathrm{O}_{2}$ group, and it was $159.02 \%$ compared to the control group, it could be significantly lessened to $122.96 \%$ with astaxanthin supplementation $\left(\mathrm{H}_{2} \mathrm{O}_{2}+\right.$ AST group) $(P<0.05)$ (Fig. 2).

\section{Whole-body composition}

Whole-body composition of golden pompano fed different dietary astaxanthin levels are shown in Table 3 . There were no significant differences in whole-body composition of fish between the two diet treatments $(P>0.05)$.

Table 2 Growth performance and survival of golden pompano fed diets with and without supplementation of astaxanthin

\begin{tabular}{|c|c|c|}
\hline $\begin{array}{l}\text { Diets } \\
\left(\text { AST } \mathrm{mg} \mathrm{kg}^{-1}\right)\end{array}$ & $\begin{array}{l}\text { Diet } 1 \\
0\end{array}$ & $\begin{array}{l}\text { Diet } 2 \\
200\end{array}$ \\
\hline IBW (g) & $32.72 \pm 0.21$ & $32.58 \pm 0.06$ \\
\hline FBW (g) & $63.71 \pm 0.66 a$ & $67.23 \pm 0.22 b$ \\
\hline WG (\%) & $95.30 \pm 0.02 a$ & $106.36 \pm 0.01 b$ \\
\hline SGR (\% day $\left.{ }^{-1}\right)$ & $1.59 \pm 0.02 \mathrm{a}$ & $1.72 \pm 0.01 b$ \\
\hline FCR & $1.78 \pm 0.02 a$ & $1.53 \pm 0.02 b$ \\
\hline SR (\%) & $97.78 \pm 0.01$ & $96.67 \pm 0.00$ \\
\hline HSI (\%) & $1.13 \pm 0.06 a$ & $0.94 \pm 0.03 b$ \\
\hline VSI (\%) & $5.97 \pm 0.11 a$ & $5.42 \pm 0.15 b$ \\
\hline $\mathrm{CF}(\mathrm{g} / \mathrm{cm} 3)$ & $3.4 \pm 0.06 a$ & $3.04 \pm 0.05 b$ \\
\hline
\end{tabular}

Values are mean \pm SEM of four replicates, and values in the same row with different letters are significant different $(P<0.05)$. Diet 1 meant golden pompano groups fed diets without supplementation of astaxanthin (AST). Diet 2 meant groups with supplementation of astaxanthin

IBW initial body weight, FBW final body weight, WG weight gain, SGR special growth rate, $F C R$ feed conversion ratio, $S R$ survival rate, $H S I$ hepatosomatic index, VSI viscerosomatic index, CF condition factor 


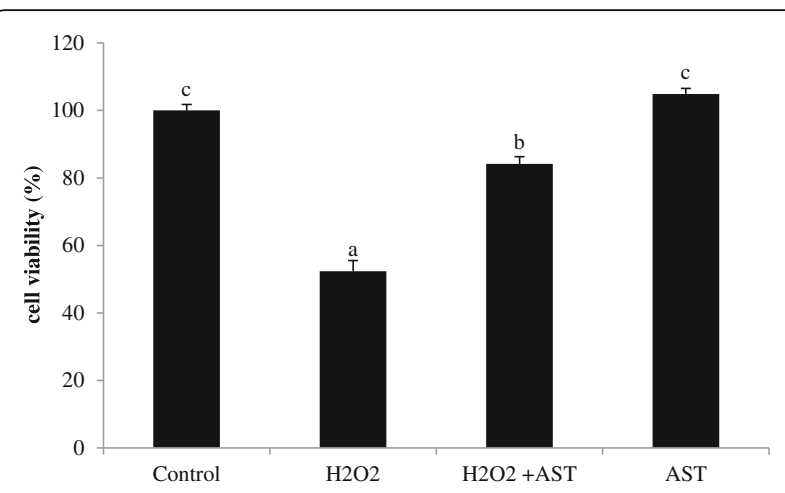

Fig. 1 The relative cell viability in different groups. Control column meant treating with neither $\mathrm{H}_{2} \mathrm{O}_{2}$ nor AST, $\mathrm{H}_{2} \mathrm{O}_{2}$ column with $\mathrm{H}_{2} \mathrm{O}_{2}$ only, $\mathrm{H}_{2} \mathrm{O}_{2}+$ AST column with both $\mathrm{H}_{2} \mathrm{O}_{2}$ and AST, and AST column with AST only. Data are expressed as mean \pm SEM of three replicates; values in the column sharing the same superscript letter are not significantly different; however, values in the column with the different superscript letter are significantly different

\section{Antioxidant capacity analysis in vivo}

The antioxidant status of juvenile pompano in vivo study are presented in Table 4. The hepatic total antioxidant capacity (T-AOC) and the reduced glutathione (GSH) in fish fed diet supplemented with astaxanthin were significantly higher than that of fish fed the control diet $(P<0.05)$. On the contrary, superoxide dismutase (SOD) declined with astaxanthin supplementation significantly $(P<0.05)$, while hepatic malondialdehyde (MDA) content was not affected by astaxanthin supplementation $(P>0.05)$.

\section{Antioxidant capacity analysis in vitro}

The antioxidant status of hepatocytes in the vitro study are shown in Table 5. The $\mathrm{H}_{2} \mathrm{O}_{2}$ as an oxidizing agent can totally damage the healthy cells, and astaxanthin, an

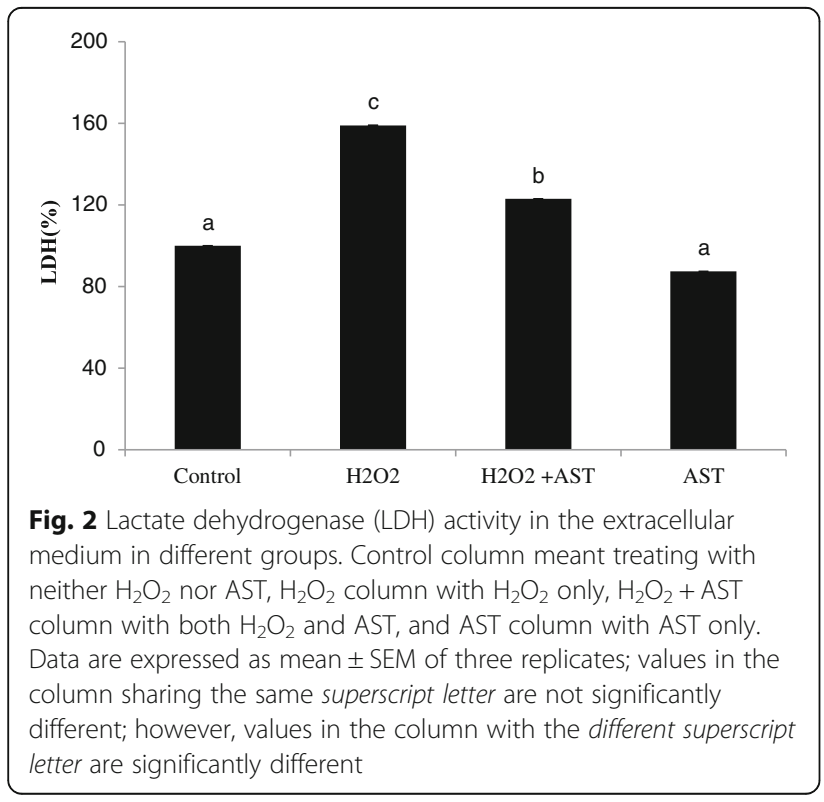

antioxidant, can repair the cells from the oxidative stress. The total antioxidant capacity (T-AOC) and the reduced glutathione $(\mathrm{GSH})$ of oxidative stress group $\left(\mathrm{H}_{2} \mathrm{O}_{2}\right)$ were the lowest and significantly lower than those of the control group $(P<0.05)$, but it could be significantly improved by astaxanthin supplementation $\left(\mathrm{H}_{2} \mathrm{O}_{2}+\right.$ AST group) $(P<0.05)$. The astaxanthin supplemented groups were significant higher than the other ones $(P<0.05)$. The SOD and MDA showed the highest value in $\mathrm{H}_{2} \mathrm{O}_{2}$ group, which were significantly higher than those in the control group $(P<0.05)$, but it also could be significantly modified by astaxanthin supplementation $\left(\mathrm{H}_{2} \mathrm{O}_{2}+\mathrm{AST}\right.$ group $)(P<0.05)$. The astaxanthin supplemented groups showed the significantly higher antioxidant capacity than the other groups $(P<$ $0.05)$.

\section{Discussion}

\section{Growth performance and proximate composition}

Carotenoids are reported to improve growth performance of fish with the reason that carotenoids may exert a positive influence on intermediary metabolism in aquatic animals (Segner et al. 1989), which enhance nutrient utilization, ultimately resulting in improving growth (Amar et al. 2001). The other possible mechanism may be to adjust the intestinal flora breaking down indigestible feed components to extract more nutrients and to stimulate the production of enzymes transporting fats for growth instead of storage (James et al. 2006). Kalinowski et al. (2011) believed that astaxanthin could enhance lipid utilization in whole fish and liver, providing more energy and consequently enhancing growth performance. In the present experiment, the growth performance (FBW, WG, and SGR) and feed utilization of fish fed diet with supplemental astaxanthin were significantly higher than that of fish fed the control diet. This result was in agreement with those in previous studies on Atlantic salmon (Christiansen and Torrissen 1996), red porgy (Kalinowski et al. 2011), Astronotus ocellatus (Alishahi et al. 2015), and large yellow croaker (Li et al. 2014). However, effect of carotenoids on fish growth is controversial. Many earlier studies have reported that dietary astaxanthin has no significant influence on growth and flesh composition of fish (Tejera et al. 2007;

Table 3 Whole-body compositions (\% dry weight) of golden pompano fed diets with and without supplementation of astaxanthin

\begin{tabular}{lllll}
\hline & Protein & Lipid & Ash & Moist \\
\hline Diet 1 & $61.77 \pm 1.17$ & $26.68 \pm 0.17$ & $17.71 \pm 0.23$ & $70.19 \pm 1.17$ \\
Diet 2 & $61.68 \pm 1.35$ & $26.33 \pm 0.46$ & $17.41 \pm 0.94$ & $71.68 \pm 1.15$
\end{tabular}

Values are mean \pm SEM of four replicates, and values in the same column with different letters are significant different $(P<0.05)$. Diet 1 meant golden pompano groups fed diets without supplementation of astaxanthin (AST). Diet 2 meant groups with supplementation of astaxanthin 
Table 4 Hepatic antioxidant statuses of golden pompano fed diets with and without supplementation of astaxanthin

\begin{tabular}{lcccr}
\hline & T-AOC (U/mg protein) & SOD $(\mathrm{U} / \mathrm{mg}$ protein) & GSH ( $\mu \mathrm{mol} / \mathrm{g}$ protein) & MDA (nmol/mg protein) \\
\hline Diet 1 & $0.11 \pm 0.01 \mathrm{a}$ & $240.87 \pm 5.76 \mathrm{a}$ & $82.44 \pm 4.87 \mathrm{a}$ & $0.41 \pm 0.02$ \\
Diet 2 & $0.15 \pm 0.01 \mathrm{~b}$ & $214.24 \pm 5.71 \mathrm{~b}$ & $118.52 \pm 8.93 \mathrm{~b}$ & $0.41 \pm 0.06$ \\
\hline
\end{tabular}

Values are mean \pm SEM of four replicates, and values in the same column with different letters are significant different $(P<0.05)$. Diet 1 meant golden pompano groups fed diets without supplementation of astaxanthin (AST). Diet 2 meant groups with supplementation of astaxanthin

$T-A O C$ total antioxidant capacity, GSH reduced glutathione, SOD superoxide dismutase, MDA malondialdehyde

Zhang et al. 2012; Pham et al. 2014; Yi et al. 2014). Kop and Durmaz (2008) believed that the effectiveness of carotenoids in terms of deposition and physiological function is species-specific in fish and not all fish species possess the same pathways for the metabolism of carotenoids. The mechanisms related to these findings have not yet been clearly elucidated. Our latest research results showed that the dietary astaxanthin can increase the apparent digestibility coefficient of the diet and further promote the expression of insulin-like growth factors (IGFs); moreover, as members of the family of transforming growth factors $\beta$, myostatin is affected by dietary astaxanthin (unpublished data).

\section{Antioxidant capacity analysis}

$\mathrm{H}_{2} \mathrm{O}_{2}$ is a strong oxidizer, produced in cell metabolism, but the excessive dose may be cytotoxic. As is shown, cell viability was sharply decreased with $\mathrm{H}_{2} \mathrm{O}_{2}$ supplemented and the increased LDH leakage into the extracellular media by $\mathrm{H}_{2} \mathrm{O}_{2}$ indicated the occurrence of oxidative stress membrane damage in our present in vitro study. Cellular antioxidative defense mechanisms can intercept the ROS both enzymatically and nonenzymatically. Total antioxidant capacity (T-AOC) is an overall indicator of the antioxidant status of an individual, representing the level of enzyme and nonenzyme original antioxidantin of the body (Xiao et al. 2004). As the value increases, the antioxidant defense against free radical reaction and reactive oxygen intermediates increases (Chien et al. 2003). In both of the in vivo and in vitro study, the T-AOC in the liver of the fish and in the hepatocytes supplemented with astaxanthin were higher, meaning that astaxanthin can improve the antioxidant status whether in vivo or in vitro. Although
$\mathrm{H}_{2} \mathrm{O}_{2}$ may decrease the total antioxidant capacity, the supplementation of astaxanthin can repair it to the same level with the control group.

The stress response might increase free radical contents, which may result in the increase of the lipid peroxidation content and lipid peroxidation injury (Liu et al. 2010). Malondialdehyde (MDA) is a product of lipid peroxidation, through crosslinking with the nucleophilic groups of proteins, nucleic acids, and amino phospholipids, accumulation of MDA leads to cell toxicity, accelerating the damage of cells and tissues (Buege and Aust 1978). The antioxidants and antioxidant enzyme system can play a significant role in resisting lipid oxide damage (Liu et al. 2010). Carotenoids may serve as an antioxidant in systems containing unsaturated fatty acids to quench free radicals (Mansour et al. 2006). The results showed that the MDA were not significant different when no stress appeared in the present in vivo study. However, once the cells suffered from oxidative stress in the present in vitro study, the MDA was increased and the cell viability was decreased, but supplemented astaxanthin could totally decrease the MDA value and save cells from the stress. Increased T-AOC and decreased MDA in the in vitro study reflected that supplemented astaxanthin in media can be totally conducive to eliminate the reactive oxygen species and protect the hepatocytes of golden pompano from free radicals. The MDA in $\left(\mathrm{H}_{2} \mathrm{O}_{2}+\mathrm{AST}\right)$ group was lower than that in $\mathrm{H}_{2} \mathrm{O}_{2}$ group, which indicated that AST can alleviate the lipid oxide damage.

Superoxide dismutase (SOD), a cytosolic enzyme that is specific for scavenging superoxide radicals, is the first enzymes to respond against oxygen radicals and important endogenous antioxidants for protection against

Table 5 The antioxidant statuses of hepatocytes treated with or without astaxanthin and $\mathrm{H}_{2} \mathrm{O}_{2}$ supplementation

\begin{tabular}{lllrl}
\hline & T-AOC & GSH ( $\mu$ mol/g protein) & MDA (nmol/mg protein) \\
\hline Control & $0.35 \pm 0.01 \mathrm{~b}$ & $\begin{array}{l}\text { SOD } \\
(\mathrm{U} / \mathrm{mg} \text { protein) }\end{array}$ & $17.81 \pm 0.83 \mathrm{~b}$ & $0.13 \pm 0.01 \mathrm{a}$ \\
$\mathrm{H}_{2} \mathrm{O}_{2}$ & $0.22 \pm 0.02 \mathrm{a}$ & $32682.76 \pm 127.04 \mathrm{~b}$ & $5.92 \pm 0.91 \mathrm{a}$ & $0.40 \pm 0.01 \mathrm{c}$ \\
$\mathrm{H}_{2} \mathrm{O}_{2}+\mathrm{AST}$ & $0.37 \pm 0.01 \mathrm{bc}$ & $2726.34 \pm 74.17 \mathrm{~b}$ & $28.24 \pm 1.11 \mathrm{c}$ & $0.23 \pm 0.01 \mathrm{bc}$ \\
AST & $0.41 \pm 0.01 \mathrm{c}$ & $2312.19 \pm 69.94 \mathrm{a}$ & $136.51 \pm 4.11 \mathrm{~d}$ & $0.12 \pm 0.01 \mathrm{a}$ \\
\hline
\end{tabular}

Values are mean \pm SEM of three replicates, and values in the same column with different letters are significant different $(P<0.05)$. Control meant golden pompano groups fed diets without supplementation of astaxanthin (AST). Control groups meant treating with neither $\mathrm{H}_{2} \mathrm{O}_{2}$ nor $A S T, \mathrm{H}_{2} \mathrm{O}_{2}$ groups meant treating with $\mathrm{H}_{2} \mathrm{O}_{2}$ only, $\mathrm{H}_{2} \mathrm{O}_{2}+$ AST groups meant treating with both $\mathrm{H}_{2} \mathrm{O}_{2}$ and AST, and AST groups meant treating with AST only

$T-A O C$ total antioxidant capacity, GSH reduced glutathione, SOD superoxide dismutase, MDA malondialdehyde 
oxidative stress (Winston and Di Giulio 1991). Lygren et al. showed that high levels of dietary fat-soluble antioxidants, such as astaxanthin and vitamin $\mathrm{E}$, there was a reduced need for endogenous antioxidant enzymes, such as total SOD (Lygren et al. 1999). The higher the SOD value, the more superoxide radicals need to be reacted (Qingming et al. 2010). It was found that the activities of liver SOD were significantly decreased by dietary astaxanthin supplementation in olive flounder (Paralichthys olivaceus) (Pham et al. 2014); large yellow croaker (Pseudosciaena crocea) (Li et al. 2014) and rainbow trout (Oncorhynchus mykiss) (Zhang et al. 2012). In this present study, SOD was significant lower in vivo and vitro study both supplemented with astaxanthin, implying that astaxanthin can eliminate reactive oxygen species to avoid the cells and tissues to produce more SOD. Once suffering from oxidative stress, the cells may produce much more endogenous SOD, as is shown in the study, to protect the body or cells from being hurt.

Glutathione (GSH), ubiquitous non-enzymatic antioxidants in the cells, is known to play an important role in the scavenging of free radicals and thus protect the important cellular macromolecules and organelles from oxidative damage (Misra and Niyogi 2009). Its role in the detoxification of ROS is important (Mallikarjuna et al. 2009). When suffered from oxidative stress, GSH was significantly lower in the present in vitro study. One mechanism for oxidative stress induced GSH depletion may involve enhanced utilization of GSH for the detoxification of free radicals and other oxidants produced as a result of $\mathrm{H}_{2} \mathrm{O}_{2}$ exposure (Shaw 1989). Vogt suggested that the increase of lipid peroxidation was not apparent until after GSH levels had been depleted (Vogt and Richie 2007). Astaxanthin can improve the GSH content in both our in vivo and in vitro study.

\section{Conclusions}

In conclusion, dietary astaxanthin supplementation can improve the growth performance of golden pompano. Moreover, astaxanthin can improve their hepatic antioxidant capacity in both vivo and vitro study by eliminating the reactive oxygen species.

\section{Abbreviations \\ AST: Astaxanthin; CF: Condition factor; FBW: Final body weight; FCR: Feed conversion ratio; GSH: Reduced glutathione; HSI: Hepatosomatic index; IBW: Initial body weight; LDH: Lactate dehydrogenase; MDA: Malondialdehyde; ROS: Reactive oxygen species; SGR: Special growth rate; SOD: Superoxide dismutase; TAOC: Total antioxidant capacity; TBARS: Thiobarbituric-acid-reacting substances; TNB: 5-Thio-2-nitrobenzoate; WG: Weight gain; VSI: Viscerosomatic index}

\section{Acknowledgements}

All authors thank the funding of the Project of Science and Technology of Guangdong Province (2013B090500110, 2013B090600045), the Central Institutes of Public Welfare Projects (2014A08YQ02), and the Special Project of Marine Fishery Science and Technology of Guangdong Province (A201601C11).

\section{Funding}

The design of the study and collection, analysis, interpretation of data, and writing the manuscript were supported by the Project of Science and Technology of Guangdong Province (2013B090500110, 2013B090600045), the Central Institutes of Public Welfare Projects (2014A08YQ02), and the Special Project of Marine Fishery Science and Technology of Guangdong Province (A201601C11)

\section{Authors' contributions}

JN, JW, and YW designed the study. JJX wrote the article. JJX, QQL, and XC performed the experiment. JN and JJX analyzed and interpreted the data. All authors have read, commented upon, and approved the final article.

\section{Competing interests}

The authors declare that they have no competing interests.

\section{Consent for publication \\ Not applicable}

\section{Ethics approval and consent to participate}

All experimental procedures were conducted in conformity with institutional guidelines for the care and use of laboratory animals in Sun Yat-sen University, Guangzhou, China, and conformed to the National Institutes of Health Guide for Care and Use of Laboratory Animals (publication no. 85-23, revised 1985)

\section{Publisher's Note}

Springer Nature remains neutral with regard to jurisdictional claims in published maps and institutional affiliations.

\section{Author details}

${ }^{1}$ South China Sea Fisheries Research Institute, Chinese Academy of Fishery Sciences, Guangzhou 510300, China. ${ }^{2}$ School of Life Science and Technology, Shanghai Ocean University, Shanghai 201306, China. Institute of Aquatic Economic Animals, School of Life Science, Sun Yat-sen University, NO.135 at Xingang Xi Road, Haizhu District, Guangzhou 510275, Guangdong Province, China.

Received: 25 January 2017 Accepted: 18 April 2017

Published online: 26 April 2017

\section{Reference}

Alishahi M, Karamifar M, Mesbah M. Effects of astaxanthin and Dunaliella salina on skin carotenoids, growth performance and immune response of Astronotus ocellatus. Aquac Int. 2015;23(5):1239-48.

Amar E, Kiron V, Satoh S, Watanabe T. Influence of various dietary synthetic carotenoids on bio-defence mechanisms in rainbow trout, Oncorhynchus mykiss (Walbaum). Aquacult Res. 2001:32(s1):162-73.

Baker R, Pfeiffer A-M, Schöner F-J, Smith-Lemmon L. Pigmenting efficacy of astaxanthin and canthaxanthin in fresh-water reared Atlantic salmon, Salmo salar. Anim Feed Sci Technol. 2002;99(1):97-106.

Britton G. Structure and properties of carotenoids in relation to function. FASEB J. 1995;9(15):1551-8.

Buege JA, Aust SD. Microsomal lipid peroxidation. Methods Enzymol. 1978;52: 302-10.

Chen YY, Lee PC, Wu YL, Liu LY. In vivo effects of free form astaxanthin powder on anti-oxidation and lipid metabolism with high-cholesterol diet. PLoS One. 2015;10(8):e0134733.

Chew BP. Antioxidant vitamins affect food animal immunity and health. J Nutr. 1995;125(6 Suppl):1804S-8S.

Chew BP, Park JS. Carotenoid action on the immune response. J Nutr. 2004; 134(1):257S-61S

Chien Y-H, Pan C-H, Hunter B. The resistance to physical stresses by Penaeus monodon juveniles fed diets supplemented with astaxanthin. Aquaculture. 2003;216(1):177-91.

Christiansen R, Torrissen OJ. Growth and survival of Atlantic salmon, Salmo salar L. fed different dietary levels of astaxanthin. Juveniles. Aquacult Nutr. 1996; 2(1):55-62.

Finkel T. Oxidant signals and oxidative stress. Curr Opin Cell Biol. 2003;15(2):247-54. Huo-sheng Y. Studies on the culture of pompano, Trachinotus ovatus [J]. J Fujian Fish. 2006;1:009. 
James R., Sampath K., Thangarathinam R. and Vasudevan I. Effect of dietary spirulina level on growth, fertility, coloration and leucocyte count in red swordtail, Xiphophorus helleri. 2006;58(2):97-104.

Kalinowski CT, Robaina LE, Izquierdo MS. Effect of dietary astaxanthin on the growth performance, lipid composition and post-mortem skin colouration of red porgy Pagrus pagrus. Aquac Int. 2011;19(5):811-23.

Kop A, Durmaz Y. The effect of synthetic and natural pigments on the colour of the cichlids (Cichlasoma severum sp., Heckel 1840). Aquac Int. 2008;16(2):117-22.

Latimer GW. Official methods of analysis of AOAC International. Maryland: AOAC International; 2012

Leite M, De Lima A, Massuyama M, Otton R. In vivo astaxanthin treatment partially prevents antioxidant alterations in dental pulp from alloxan-induced diabetic rats. Int Endod J. 2010;43(11):959-67.

Li M, Wu W, Zhou P, Xie F, Zhou Q, Mai K. Comparison effect of dietary astaxanthin and Haematococcus pluvialis on growth performance, antioxidant status and immune response of large yellow croaker Pseudosciaena crocea. Aquaculture. 2014;434:227-32.

Lin HZ, Tan XH, Zhou CP, Niu J, Xia DM, Huang Z, Wang J, Wang Y. Effect of dietary arginine levels on the growth performance, feed utilization, nonspecific immune response and disease resistance of juvenile golden pompano Trachinotus ovatus. Aquaculture. 2015:437:382-9.

Liu C, Chen C. The biology and cultured technology of Pompano (Trachinotus ovatus). Shandong Fisheries. 2009;26:32-3.

Liu B, Xie J, Ge X, Xu P, Wang A, He Y, Zhou Q, Pan L, Chen R. Effects of anthraquinone extract from Rheum officinale Bail on the growth performance and physiological responses of Macrobrachium rosenbergii under high temperature stress. Fish Shellfish Immunol. 2010;29(1):49-57.

Lygren B, Hamre K, Waagbø R. Effects of dietary pro-and antioxidants on some protective mechanisms and health parameters in Atlantic salmon. J Aquat Anim Health. 1999;11(3):211-21.

Mallikarjuna K, Nishanth K, Hou CW, Kuo CH, Sathyavelu RK. Effect of exercise training on ethanol-induced oxidative damage in aged rats. Alcohol. 2009:43(1):59-64.

Mansour N, McNiven MA, Richardson GF. The effect of dietary supplementation with blueberry, a-tocopherol or astaxanthin on oxidative stability of Arctic char (Salvelinus alpinus) semen. Theriogenology. 2006;66(2):373-82.

Marklund S, Marklund G. Involvement of the superoxide anion radical in the autoxidation of pyrogallol and a convenient assay for superoxide dismutase. Eur J Biochem. 1974:47(3):469-74.

Martinez-Alvarez RM, Morales AE, Sanz A. Antioxidant defenses in fish: biotic and abiotic factors. Rev Fish Biol Fish. 2005;15(1-2):75-88.

Misra S, Niyogi S. Selenite causes cytotoxicity in rainbow trout (Oncorhynchus mykiss) hepatocytes by inducing oxidative stress. Toxicol In Vitro. 2009;23(7):1249-58.

Niu J, Du Q, Lin HZ, Cheng YQ, Huang Z, Wang Y, Wang J, Chen YF. Quantitative dietary methionine requirement of juvenile golden pompano Trachinotus ovatus at a constant dietary cystine level. Aquacult Nutr. 2013;19(5):677-86

Niu J, Figueiredo-Silva C, Dong Y, Yue Y, Lin H, Wang J, Wang Y, Huang Z, Xia D, Lu $X$. Effect of replacing fish meal with soybean meal and of DL-methionine or lysine supplementation in pelleted diets on growth and nutrient utilization of juvenile golden pompano (Trachinotus ovatus). Aquacult Nutr. 2016:22:606-14.

Olmedilla B, Granado F, Southon S, Wright AJA, Blanco I, Gil-Martinez E, Berg H v d, Corridan B, Roussel A-M, Chopra M, Thurnham DI. Serum concentrations of carotenoids and vitamins $A, E$, and $C$ in control subjects from five European countries. Br J Nutr. 2007:85(02):227.

Pham MA, Byun HG, Kim KD, Lee SM. Effects of dietary carotenoid source and level on growth, skin pigmentation, antioxidant activity and chemical composition of juvenile olive flounder Paralichthys olivaceus. Aquaculture. 2014;431:65-72.

Qi C-L, Lin H-Z, Huang Z, Zhou C-P, Wang Y, Wang J, Niu J, Zhao S-Y. Effects of dietary arachidonic acid levels on growth performance, whole-body proximate composition, digestive enzyme activities and gut morphology of juvenile golden pompano trachinotus. Isr J Aquacult Bamidgeh. 2016;68: 1275-84.

Qingming Y, Xianhui P, Weibao K, Hong Y, Yidan S, Li Z, Yanan Z, Yuling Y, Lan D, Guoan L. Antioxidant activities of malt extract from barley (Hordeum vulgare L.) toward various oxidative stress in vitro and in vivo. Food Chem. 2010;118(1):84-9.

Robinson EH, Wilson RP, Poe WE. Arginine requirement and apparent absence of a lysine-arginine antagonist in fingerling channel catfish. J Nutr. 1981;111(1):46-52.

Segner $\mathrm{H}$, Arend P, Von Poeppinghausen K, Schmidt H. The effect of feeding astaxanthin to Oreochromis niloticus and Colisa labiosa on the histology of the liver. Aquaculture. 1989;79(1-4):381-90.

Shaw S. Lipid peroxidation, iron mobilization and radical generation induced by alcohol. Free Radic Biol Med. 1989;7(5):541-7.
Shimidzu N, Goto M, Miki W. Carotenoids as singlet oxygen quenchers in marine organisms. Fish Sci. 1996;62(1):134-7.

Tejera N, Cejas JR, Rodríguez C, Bjerkeng B, Jerez S, Bolaños A, Lorenzo A. Pigmentation, carotenoids, lipid peroxides and lipid composition of skin of red porgy (Pagrus pagrus) fed diets supplemented with different astaxanthin sources. Aquaculture. 2007;270(1):218-30.

Tutman P, Glavić N, Kožul V, Skaramuca B, Glamuzina B. Preliminary information on feeding and growth of pompano, Trachinotus ovatus (Linnaeus, 1758)(Pisces; Carangidae) in captivity. Aquac Int. 2004;12(4-5):387-93.

Vardi N, Parlakpinar H, Ozturk F, Ates B, Gul M, Cetin A, Erdogan A, Otlu A. Potent protective effect of apricot and beta-carotene on methotrexate-induced intestinal oxidative damage in rats. Food Chem Toxicol. 2008;46(9):3015-22.

Vogt BL, Richie Jr JP. Glutathione depletion and recovery after acute ethanol administration in the aging mouse. Biochem Pharmacol. 2007;73(10):1613-21.

Wan X, Ma T, Wu W, Wang Z. EROD activities in a primary cell culture of grass carp (Ctenopharyngodon idellus) hepatocytes exposed to polychlorinated aromatic hydrocarbonas. Ecotoxicol Environ Saf. 2004;58(1):84-9.

Wang F, Han H, Wang Y, Ma X. Growth, feed utilization and body composition of juvenile golden pompano Trachinotus ovatus fed at different dietary protein and lipid levels. Aquacult Nutr. 2013;19(3):360-7.

Winston GW, Di Giulio RT. Prooxidant and antioxidant mechanisms in aquatic organisms. Aquat Toxicol. 1991;19(2):137-61.

Xiao N, Wang XC, Diao YF, Liu R, Tian KL. Effect of initial fluid resuscitation on subsequent treatment in uncontrolled hemorrhagic shock in rats. Shock. 2004;21(3):276-80.

Yi XW, Xu W, Zhou HH, Zhang YJ, Luo YW, Zhang WB, Mai KS. Effects of dietary astaxanthin and xanthophylls on the growth and skin pigmentation of large yellow croaker Larimichthys croceus. Aquaculture. 2014;433:377-83.

Zhang J, Li X, Leng X, Zhang C, Han Z, Zhang F. Effects of dietary astaxanthins on pigmentation of flesh and tissue antioxidation of rainbow trout (Oncorhynchus mykiss). Aquac Int. 2012;21(3):579-89.

Zhou CP, Ge XP, Niu J, Lin HZ, Huang Z, Tan XH. Effect of dietary carbohydrate levels on growth performance, body composition, intestinal and hepatic enzyme activities, and growth hormone gene expression of juvenile golden pompano. Trachinotus ovatus Aquaculture. 2015:437:390-7.

\section{Submit your next manuscript to BioMed Central and we will help you at every step:}

- We accept pre-submission inquiries

- Our selector tool helps you to find the most relevant journal

- We provide round the clock customer support

- Convenient online submission

- Thorough peer review

- Inclusion in PubMed and all major indexing services

- Maximum visibility for your research

Submit your manuscript at www.biomedcentral.com/submit
) Biomed Central 